\title{
RESISTÊNCIA DE SOJA A INSETOS. IV. COMPORTAMENTO DE CULTIVARES E LINHAGENS EM RELAÇÃO A HEDILEPTA INDICATA (FABR.) (')
}

\author{
ANDRE LUIZ LOURENÇĀO $\left({ }^{2,4}\right)$, CARLOS JORGE ROSSETTO $\left({ }^{2}\right)$ \\ e MANOEL ALBINO COELHO DE MIRANDA $\left({ }^{3,4}\right)$
}

\begin{abstract}
RESUMO
Em condições de campo e de telado, estudou-se o comportamento das seguintes linhagens e cultivares de soja em relação à lagarta-enroladeira, Hedilepto indicata (Fabr., 1775): PI 227687, IAC 73-228, IAC 79-1823, 'Santa Rosa', IAC 80-596-2, 'IAC 12', 'IAC 8', IAC 78-2318, D 72-9601-1, PI 171451, 'IAC São Carlos' e PI 229358, quanto ao número de pontos de ataque do inseto. Tanto no campo como em telado, IAC 73-228 e PI 229358 apresentaram, respectivamente, o menor e o maior valor. Em condições de campo, PI 227687 e IAC 73-228 sofreram as menores perdas de área foliar devidas ao ataque de $H$. indicata, enquanto 'IAC São Carlos', PI 171451 e PI 229358 se mostratam como os mais suscetíveis. Em outro experimento conduzido em campo, utilizando-se PI 274454, PI 274453, IAC 73-228, 'IAC 12', IAC 80-596-2, 'UFV-1', IAC 78-2318 e 'Paraná', os dois primeiros apresentaram alto nivel de resistência ao inseto, superior ao exibido por IAC 73-228, sendo que 'Paraná' teve a maior perda de área foliar. Ainda em oondiçōes de campo, em área de seleção de plantas $F_{2}$ descendentes do cruzamento de 'Paraná' com PI 274453 , foram avaliadas, individualmente, plantas quanto à área foliar comida: os resultados obtidos sugerem que a resistência da PI 274453 a $H$. indicata seja devida a um gene dominante.
\end{abstract}

Termos de indexação: soja; Glycine max (L.) Merrill; resistência varietal; lagarta-enroladeira; Hedilepta indicata (Fabr.)

(1) Trabalho apresentado ao IX Congresso Brasileiro de Entomologia, realizado em Londrina (PR), 22-27 de junho de 1984. Recebido para publicação em 28 de dezembro de 1983.

${ }^{2}$ ) Seção de Entomologia Fitotécnica, Instituto Agronômico (IAC), Caixa Postal 28, 13.100 Campinas (SP).

$\left(\begin{array}{l}3 \\ 4\end{array}\right)$ Seção de Leguminosas, IAC.

$\left({ }^{4}\right)$ Bolsista do CNPq. 


\section{INTRODUÇÃO}

Espécie de ampla distribuição geográfica, a lagarta-enroladeira, $\mathrm{He}$ dilepta indicata (Fabr., 1775) (Lepidoptera: Pyralidae), tem como hospedeiros leguminosas nativas e cultivadas: alimentando-se do parênquima das folhas, que enrola ou junta mediante fios de seda, permanece protegida em seu interior.

H. indicata é citada como praga secundária da soja, já que sua incidência nessa cultura normalmente se limita a baixas infestaçōes sem causar danos econômicos. Todavia, nos últimos anos, a densidade populacional tem aumentado sensivelmente em diversas regiōes, culminando com uma alta e generalizada infestação durante a safra 1982/83.

Enfocando-se seu controle por meio de resistência varietal, procurou-se avaliar o comportamento de linhagens e cultivares de soja em relação ao ataque desse inseto.

\section{MATERIAL E MÉTODOS}

Os cultivares e linhagens de soja estudados estão apresentados, juntamente com seus progenitores, nos quadros 1 e 2 . Procurou-se avaliar o comportamento de material com resistência a um ou mais insetos, além de linhagens em desenvolvimento no Instituto Agronômico e cultivares já difundidos.

As linhagens e cultivares resistentes abrangem PI 171451, PI 227687 e PI 229358, com resistência múltipla a insetos (ANNUAL REPORT FOR 1980, 1981; CLARK et alii, 1972; DUYN et alii, 1971; HATCHETT et alii, 1976; JONES \& SULLIVAN, 1979; KILEN et alii, 1977; LUEDDERS \& DICKERSON, 1977; ROSSETTO et alii, 1981; ROSSETTO et alii, 1977); PI 274454, provável fonte de resistência a percevejos pentatomídeos (ROSSETTO et alii, 1981), IAC 73-228, 'IAC 12', IAC 80-596-2, materiais com diferentes graus de resistência a percevejos pentatomídeos (LOURENÇÃO et alii, 1985; MIRANDA et alii, 1979; ROSSETTO et alii, 1981), IAC 78-2318, linhagem pouco atacada pela broca dos ponteiros Epinotia apore$m a$ (Wals.) (LOURENÇÃO \& MIRANDA, 1983), e D 72-9601-1, linhagem selecionada nos EUA para resistência a Pseudoplusia includens (Walker). D 72-9601-1 já foi testada no Brasil para lagartas desfolhadoras com resultado positivo (REZENDE et alii, 1980).

Três experimentos e um campo de plantas em $F_{2}$ foram conduzidos no Centro Experimental de Campinas para avaliar a reação das linhagens e cultivares a $\boldsymbol{H}$. indicata. O primeiro, com doze tratamentos (Quadro 1 ), foi 
instalado a 9.11.82, em condições de telado, usando o delineamento de blocos ao acaso, com nove repetiçōes. Cada parcela constou de uma cova com duas plantas, espaçadas de $0,6 \mathrm{~m}$ entre linhas e $0,4 \mathrm{~m}$ na linha. Cercando os blocos, usou-se o cultivar IAC-9 como bordadura. Durante a fase vegetativa, ocorreu infestação natural de $H$. indicata, que se prolongou até a fase de enchimento de grãos. A 20 e a 27.12 .82 , respectivamente a 39 e 46 dias do plantio, foram feitas avaliações do número de pontos de ataque de lagartas de $H$. indicata em cada parcela, caracterizados pelo enrolamento do folíolo ou junção de dois ou mais folíolos mediante fios de seda.

Esses doze tratamentos foram também estudados em condições de campo. A 19.11.82 instalou-se o segundo experimento, com delineamento de blocos ao acaso com oito repetiçסes. As parcelas constitu íram-se de três linhas de $3 \mathrm{~m}$, espaçadas $0,6 \mathrm{~m}$ entre si e com densidade aproximada de vinte plantas/metro. Como bordadura, cercando o campo experimental, foi plantado o cultivar IAC Foscarin-31.

O plantio do terceiro experimento deu-se a 30.12 .82 , envolvendo oito tratamentos (Quadro 2), distribuídos em blocos ao acaso com dez repetições, com parcelas idênticas às do experimento anterior. A fim de isolar o ensaio, foram plantadas linhas de 'Paraná' e da linhagem IAC 80-596-2.

A 31.12.82, foi instalado um campo de seleção de plantas $F_{2}$ obtidas de cruzamento entre 'Paraná' e PI 274453. Efetuou-se o plantio de três a quatro sementes em covas distantes $0,5 \mathrm{~m}$ entre si na linha e com espaçamento de $1 \mathrm{~m}$ entre linhas. Mediante desbaste, deixou-se apenas uma planta por cova, num total de 63 plantas $F_{2}$.

Os experimentos e o campo de plantas $F_{2}$ ficaram expostos à infestação natural de $H$. indicata, que ocorreu de maneira intensa durante os meses de fevereiro e março de 1983. Para o segundo experimento, formado por doze tratamentos em condições de campo, a 9.2 .83 foi feita avaliação do número total de pontos de ataque de $H$. indicata na linha central de cada parcela. Posteriormente, a 23, 25 e 31.3.83, foram efetuadas avaliações respectivamente no segundo e terceiro experimentos, e no campo de plantas $\mathrm{F}_{2}$, estimando-se visualmente a porcentagem de área foliar comida por $H$. indicata nas três linhas de cada parcela ou, no caso de plantas $F_{2}$, em toda a planta.

Por ocasião das avaliações dos experimentos, anotou-se o estádio de desenvolvimento das plantas, segundo COSTA \& MARCHEZAN (1982), com exceção do experimento conduzido em telado, em que se anotaram apenas as datas (20 e 27.12.82).

Para análise dos dados, as porcentagens de área foliar comida foram convertidas em arco seno $\sqrt{\% / 100}$, sendo as médias comparadas pelo teste de Tukey ao nivel de $5 \%$. 


\section{RESULTADOS E DISCUSSÃO}

Os resultados obtidos encontram-se nos quadros 1 e 2 e na figura 1 . Pelo quadro 1 , verifica-se que, em condições de campo, as menores perdas de área foliar foram da PI 227687, caracterizando nessa introdução resistência a mais uma espécie, já que havia sido apontada como resistente a diversos insetos que se alimentam de soja (ANNUAL REPORT FOR 1980, 1981; CLARK et alii, 1972; DUYN et alii, 1971, HATCHETT et alii, 1976; JONES \& SULLIVAN, 1979; KILEN et alii, 1977; LUEDDERS \& DICKERSON, 1977; ROSSETTO et alii, 1981), e da linhagem IAC 73-228, que vem sendo utilizada como fonte de resistência a percevejos pentatomídeos (LOURENÇ $\tilde{O} O$ et alii, 1985) no programa de melhoramento de soja para resistência a insetos, conduzido pelas Seções de Entomologia e de Leguminosas do Instituto Agronômico. Ainda, IAC 79-1823, linhagem que tem mostrado baixo desfolhamento causado por besouros crisomelídeos em ensaios preliminares, teve bom comportamento em relação a $H$. indicata, situando-se entre os materiais menos atacados. IAC 80-596-2, linhagem selecionada para resistência a percevejos (LOURENÇAO et alii, 1985), apresentou comportamento intermediário, a exemplo do 'Santa Rosa', 'IAC 12', 'IAC 8' e IAC 78-2318. As linhagens PI 171451 e PI 229358 mostraram alta suscetibilidade, sendo, juntamente com 'IAC São Carlos', os materiais mais atacados nesse experimento.

Com respeito aos pontos de ataque avaliados em campo, observa-se que esses valores guardam uma associação com área foliar comida, principalmente entre os materiais resistentes e os mais suscetíveis, sendo o coeficiente de correlação $\left(\mathrm{r}^{2}\right)$ de $72,6 \%$. Para IAC $80-596-2$, que teve um alto número de pontos de ataque em comparação com sua área foliar comida, é possível que exista algum efeito adverso da planta sobre o inseto, impedindo-o de alimentar-se normalmente.

Em condições de telado, quando a maioria das plantas se encontrava no início da fase de enchimento de grãos, ocorreu, simultaneamente à infestação já existente de $H$. indicata, infestação natural de lagartas de Palustra sp. $\left({ }^{5}\right)$, cuja alimentação nas folhas mascarou os danos da lagarta-enrolar deira. Por isso, não foi feita avaliação de área foliar comida. Comparando-se as médias de pontos de ataque de telado com as obtidas em campo, verificam-se tendências semelhantes, apresentando IAC 73-228 e PI 229358, respectivamente, os menores e os maiores valores. D 72-9601-1, embora com um número muito baixo de pontos de ataque tanto em telado como em campo, nesta última condição situou-se entre os materiais de perda de área foliar intermediária.

$\left({ }^{5}\right)$ Os autores agradecem a identificação do inseto ao Dr. Vitor O. Becker, Centro de Pesquisa Agropecuária dos Cerrados, EMBRAPA. 


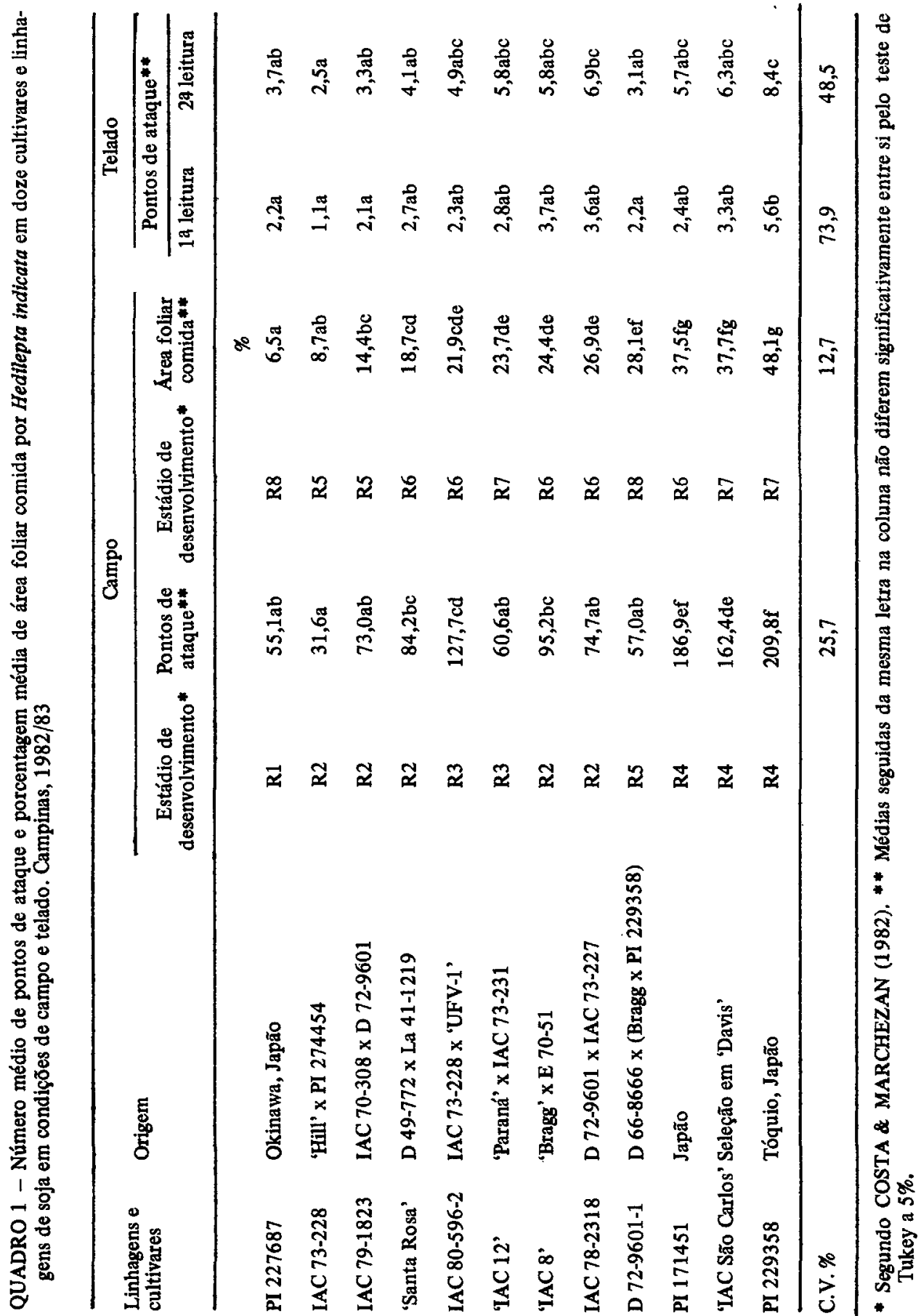




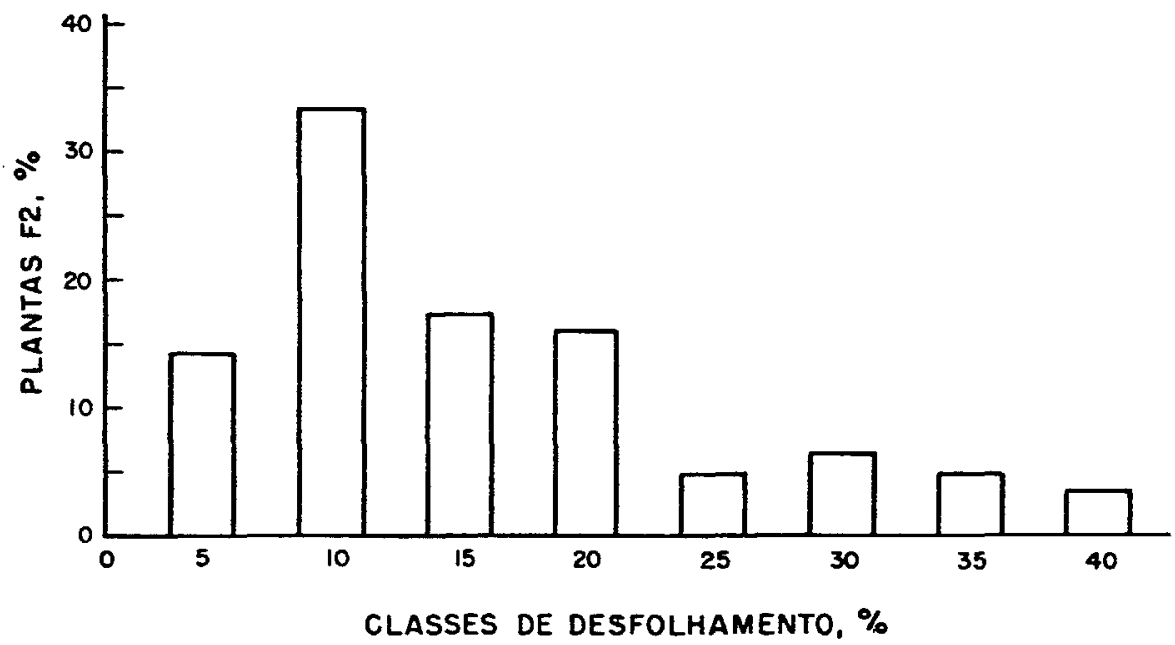

FIGURA 1 - Freqüência de plantas F2, descendentes de cruzamentos entre o cultivar Paraná e PI 274453, em oito classes de desfolhamento causado por Hedilepta indicata. Campinas, 1983

QUADRO 2 - Porcentagens médias de área foliar comida por Hedilepta indicata em oito linhagens e cultivares de soja com seus respectivos estádios de desenvolvimento na data da avaliaçao. Campinas, 1983

Linhagens e cultivares
Origem
Estádio de desenvolvimento *
Ārea foliar comida**

\section{PI 274454}

PI 274453

IAC 73-228

'IAC 12'

IAC 80-596-2

'UFV-1'

IAC 78-2318

'Paraná'
Okinawa, Japão

Okinawa, Japðo

'Hill' x PI 274454

'Paraná' x IAC 73-231

IAC 73-228 x 'UFV-1'

Seleção em 'Viçoja'

D 72-9601 X IAC 73-227

'Hill' x D 52/810
R1

V9

R5

R5

R5

R5

R5

R5
$\%$ $4,1 \mathrm{a}$

$4,6 \mathrm{a}$

$12,0 \mathrm{~b}$

$29,5 \mathrm{c}$

$31,0 \mathrm{c}$

$32,0 \mathrm{c}$

$41,8 \mathrm{~d}$

$61,5 \mathrm{e}$

C.V.\%

11,8

* Segundo COSTA \& MARCHEZAN (1982). ** Médias seguidas da mesma letra nao diferem significativamente entre si pelo teste de Tukey a $5 \%$. 
A utilização de pontos de ataque para avaliar resistência de soja a $H$. indicata, apesar de guardar boa relação com o dano direto nos extremos de resistência e suscetibilidade, não é um bom critério, pois é um método mais trabalhoso, além de exibir coeficientes de variação mais elevados que a estima tiva visual de área foliar comida.

$\mathrm{O}$ quadro 2 traz os dados referentes ao terceiro experimento. Observa-se alto nível de resistência nas PI 274454 e PI 274453, quando comparadas com os demais, principalmente com 'Paraná', que mostrou elevada suscetibilidade a esse inseto. A resistência de IAC 73-228 a $\mathrm{H}$. indicata pode ser explicada pela sua origem, já que um dos pais, PI 274454, é altamente resistente. Embora seja descendente de IAC 73-228, IAC 80-596-2 não exibiu comportamento semelhante a esse pai resistente, uma vez que, durante as etapas de sua obtenção, não foi feita seleção para resistência a esse inseto.

As freqüências de plantas $F_{2}$ descendentes dos cruzamentos entre 'Paraná' e PI 274453 com as diferentes porcentagens de área foliar comida acham-se representadas na figura 1. Notam-se dois grupos de plantas: um, com baixo dano, com perda de área foliar oscilando entre 5 e $20 \%$, e um segundo, de dano mais elevado, entre 25 e $40 \%$. Os números observados de plantas em cada um desses grupos perfazem, respectivamente, 51 e 12 . Os números esperados para uma segregação de 3:1 nesse total de plantas seriam 47,2 e 15,8. O valor do $x^{2}$ (quiquadrado) entre os números observados e esperados é 1,22, não-significativo, indicando que a resistência a $H$. indicata presente na PI 274454 seja devida a um gene dominante.

\section{SUMMARY}

RESISTANCE OF SOYBEAN TO INSECTS. IV. PERFORMANCE OF CULTIVARS AND LINES IN RELATION TO HEDILEPTA INDICATA (FABR.)

Performance of soybean cultivars and lines in relation to $H$. indicata was studied under field and screen house conditions. Differences in the number of points of attack (characterized by the rolling or junction of the folioles by means of silk secretion) were evaluated in PI 227687, IAC 73-228, IAC 79-1823, 'Santa Rosa', IAC 80-596-2, 'IAC 12', 'IAC 8', IAC 78-2318, D 72-9601-1, PI 171451, 'IAC São Carlos' and PI 229358; in both, field and screen house conditions, IAC 73-228 and PI 229358 showed, respectively, the lowest and the highest values. In the field, PI 227687 and IAC 73-228 presented low defoliation, while 'IAC São Carlos', PI 171451 and PI 229358 were highly defoliated. In another field experiment with PI 274454, PI 274453, IAC 73-228, 'IAC 12', IAC 80-596-2, 'UFV-1', IAC 78-2318 and 'Paraná', the first two varieties were highly resistant to $H$, indicata. The level of resistance of the PI's was superior to that of IAC 73-228. 'Paraná' was the most susceptible variety. Under field conditions, in an area of selection of $F_{2}$ plants descendents of crosses between 'Paraná' and PI 274453, 63 plants were evaluated in relation to the 
eaten leaf area; the results suggest that the PI 274453 resistance to $H$. indicato is inherited in this cross as dominant simple, being possible to teansfer it to commercial varieties.

Index terms: soybean; Glycine max (L.) Merrill; plant resistance; Hedilepta indicata (Fabr.), 1775)

\section{REFERÊNCIAS BIBLIOGRÁFICAS}

ANNUAL REPORT FOR 1980. Ibadan, Nigeria, International Institute of Tropical Agriculture, 1981. p.148-149.

CLARK, W.J.; HARRIS, F.A.; MAXWELL, F.G. \& HARTWIG, E.E. Resistance of certain soybean cultivars to bean leaf beetle, striped blister beetle and bollworm. Journal of Economic Entomology, 65(6): 16691672, 1972.

COSTA, J.A. \& MARCHEZAN, E. Características dos estádios de desenvolvimento da soja. Campinas, Fundação Cargill, 1982. 30p.

DUYN, J.W. van; TURNIPSEED, S.G. \& MAXWELL, J.D. Resistance in soybeans to the Mexican bean beetle. I. Sources of resistance. Crop Science, 11(4):572-573, 1971.

GAZZONI, D.L. Entomofauna da soja - Insetos-pragas e seu controle. In: MIYASAKA, S. \& MEDINA, J.C., eds. A soja no Brasil. [ Campinas, Fundação Cargill], 1981. p.569-593.

; OLIVEIRA, E.B. de; CORSO, I.C.; FERREIRA, B.S.C.; VILLAS BOAS, G.L.; MOSCARDI, F. \& PANIZZI, A.R. Manejo de pragas da soja. Londrina, Centro Nacional de Pesquisa de soja, 1982. 44p. (Circular Técnica, 05)

HATCHETT, J.H.; BELAND, G.L. \& HARTWIG, E.E. Leaf-feeding resistance to bollworm and tobacco budworm in three soybean plant introductions. Crop Science, 16(2):277-280, 1976.

JONES JR., W.A. \& SULLIVAN, M.J. Soybean resistance to the southern green stink bug, Nezara viridula, Journal of Economic Entomology, 72(4): 628-632, 1979.

KILEN, T.C.; HATCHETT, J.H. \& HARTWIG, E.E. Evaluation of early generation soybeans for resistance to soybean looper. Crop Science, 17(3): 397-398, 1977.

LOURENÇÃO, A.L. \& MIRANDA, M.A.C. de. Resistência de soja a insetos. I. Comportamento de linhagens e cultivares em relação a Epinotia aporema (Wals.) (Lepidoptera: Tortricidae). Bragantia, Campinas, 42:203209, 1983. 
LOURENÇÃO, A.L., ROSSETTO, C.J. \& MIRANDA, M.A.C. de. Resistência de soja a insetos. III. Seleção de linhagens resistentes a percevejos. Bragantia, Campinas, 44(1):77-86, 1985.

LUEDDERS, V.D. \& DICKERSON, W.A. Resistance of selected soybean genotypes and segregating populations to cabbage looper feeding. Crop Science, 17(3): 395-397, 1977.

MIRANDA, M.A.C. de; ROSSETTO, C.J.; ROSSETTO, D.; BRAGA, N.R.; MASCARENHAS, H.A.A.; TEIXEIRA, J.P.F. \& MASSORIOL, A. Resistência de soja a Nezara viridula e Piezodorus guildinii em condições de campo. Bragantia, Campinas, 38:181-188, 1979.

RAMIRO, Z.A. Pragas da soja. In: A SOJA no Brasil Central. Campinas, Fundação Cargill, 1982. p.215-270.

REZENDE, J.A.M.; MIRANDA, M.A.C. de \& MASCARENHAS, H.A.A. Comportamento de cultivares de soja em relação à área foliar comida por lagartas das folhas. Bragantia, Campinas, 39:161-165, 1980.

ROSSETTO, C.J.; LOURENÇÃO, A.L.; IGUE, T. \& MIRANDA, M.A.C. de. Picadas de alimentação de Nezara viridula em cultivares e linhagens de soja de diferentes graus de suscetibilidade. Bragantia, Campinas, 40: 109-114, 1981.

; NAGAI, V.; IGUE, T.; ROSSETTO, D. \& MIRANDA, M.A.C. de. Preferência de alimentação de adultos de Diabrotica speciosa (Germar) e Cerotoma arcuata (Oliv.) em variedades de soja. Bragantia, Campinas, 40:179-183, 1981.

ROSSETTO, D.; COSTA, A.S.; MIRANDA, M.A.C.; NAGAI, V. \& ABRAMIDES, E. Diferenças na oviposição de Bemisia tabaci em variedades de soja. Anais da Sociedade Entomológica do Brasil, 6(2):256-263, 1977. \& NAGAI, V. Ensaio de livre escolha para o coleóptero Colaspis sp. em seis variedades de soja. Bragantia, Campinas, 39:195-198, 1980. 